\title{
IX Bienal do MERCOSUL: estratégias empresariais de inserção ${ }^{1}$
}

IX Bienal do MERCOSUL: corporate insertion strategies

\section{Leonardo Mèrcher²}

\section{RESUMO}

o presente boletim versa sobre a estratégia empresarial no fortalecimento de marca utilizando-se um evento cultural. Utiliza-se o caso de três instituições europeias - Banco Santander, SAP AG e Grupo Roullier - junto à execução da IX Bienal do Mercosul, em 2013.

Palavras-chave: Empresas; Mercado Internacional; Bienal do Mercosul.

\begin{abstract}
Thisarticle versa oncorporatestrategy in strengtheningbrandusing a cultural event. We use the case ofthreeEuropeaninstitutions - Banco Santander, SAP AG andRoullierGroup alongwiththeimplementationofthe9thMercosulBiennial in 2013.
\end{abstract}

Keywords: Corporates; International Market; Bienal do MERCOSUL.

\section{Introdução}

A IX Bienal do MERCOSUL ocorreu de 13 de setembro até 10 de novembro de 2013 na cidade de Porto Alegre, no Estado do Rio Grande do Sul, Brasil. O evento, voltado para interações e mostras artísticas e culturais é organizado anualmente, desde 1997, pela Fundação Bienal do MERCOSUL. A Fundação é uma organização nãogovernamental que não possui vinculo institucional governamental direto com o MERCOSUL (Fundação Bienal do MERCOSUL, 2013), mas que, através do capital público do governo brasileiro, permite sua realização em parceria com o capital privado.

Essas parcerias entre a Fundação Bienal do MERCOSUL e o capital privado, além do capital público, problematizam a percepção de cultura regional e investimentos

\footnotetext{
${ }^{1}$ Artigo recebido em 03 de dezembro de 2013 e aceito para publicação em 02 de fevereiro de 2014.

${ }^{2}$ Mestre em Ciência Política pela Universidade Federal do Paraná, professor de Relações Internacionais no Centro Universitário Internacional, Curitiba, Brasil.

Conjuntura Global, Curitiba, Vol.2, n.4, out./dez., 2013, p. 214-221.
} 
estrangeiros dentro das relações internacionais. A partir de uma delimitação de um grupo de empresas europeias, presente na realização da IX Bienal do MERCOSUL, podese defender a ideia de que a cultura torna-se um meio para maior inserção e participação do capital estrangeiro nas sociedades locais. Asempresas europeias, portanto, são tratadas nesse boletimcomo agentes econômicos interessados nos processos de integração regional - utilizando-se do setor cultural - objetivando, possivelmente, aumento de inserção no mercado local.

Um dos principais objetivos encontrados no evento poderia ser identificado como divulgação das respectivas marcas empresariais ao público alvo (visitantes, instituições e demais empresas envolvidas). Em um segundo momento, a anexação da marca à esfera de produção cultural, como um agente social, poderia ser somada aos interesses que sustentariam essa atuação. As empresas se mostrariam participativas e contribuiriam com desenvolvimento local, sobretudo junto à percepção do público alvo.

\section{Natureza do capital envolvido}

Observando a lista de parcerias divulgada pela Fundação ${ }^{3}$, encontram-se representações das três esferas do governo brasileiro - Federal, Estadual e Municipal. As parcerias estabelecidas entre a Fundação Bienal do Mercosul e as esferas governamentais foram:

- Governo Federal, através do Ministério da Cultura;

- Governo do Estado do Rio Grande do Sul, através da Secretaria de Estado da Cultura, do Museu de Arte do Rio Grande do Sul, do Memorial do Rio Grande do Sul e de seu Museu dos Direitos Humanos do MERCOSUL, da Companhia Estadual de Energia Elétrica (Grupo CEEE) e seu Centro Cultural Érico Veríssimo;

- Governo Municipal de Porto Alegre, através da Secretaria da Cultura e da Usina do Gasômetro que abrigou boa parte das exposições durante o evento.

\footnotetext{
${ }^{3}$ Disponível em http://9bienalmercosul.art.br/pt/sobre/parceiros/. Acesso em 01/12/2013. Conjuntura Global, Curitiba, Vol.2, n.4, out./dez., 2013, p. 214-221.
} 
Percebe-se que não houve uma participação de esferas governamentais de outros Estados pertencentes ao MERCOSUL, tornando a natureza governamental do evento predominantemente brasileira. Essa natureza passa a classificar a Bienal do MERCOSUL como um evento brasileiro direcionado ao bloco, e não necessariamente um evento administrado pelo MERCOSUL. Após essa ressalva, encontra-se nas empresas a viabilização do evento, através da cooperação entre o capital público e o privado.

Além das esferas públicas, 23 instituições de capital privado estão registradas no quadro de parceiras do evento em 2013. Dessas 23 instituições, 17 seriam brasileiras e seis estrangeiras. 0 critério de identificação da natureza dessas empresas dá-se pela legislação brasileira (Instrução Normativa no 81, de 05 de janeiro de 1999 do Departamento Nacional de Registro do Comércio ${ }^{4}$, que disciplina os pedidos de autorização para nacionalização ou instalação de filial, agência, sucursal ou estabelecimento no País), ondeseria considerada uma empresa estrangeira, aquela sociedade constituída e organizada em conformidade com a legislação de seu país de origem, onde também manteria sua sede administrativa. A seguir tem-se a lista das 23 instituições divididas entre brasileiras e estrangeiras:

- Empresas Brasileiras: Braskem; Petrobrás; Gerdau; Celulose Irani; Banco Itaú; Grupo RBS de Comunicação; Canal Futura (Organizações Globo); Lojas Pompéia; Vonpar Alimentos; Transarte; Latitude; Fundação Gaúcha dos Bancos Sociais (mantida pelo Sistema FIERGS: CIERGS, SESI e SENAI); Triunfo CONCEPA (Administradora Rodoviária/Pedágio); Lojas Renner (sendo 85\% do seu capital de participação estrangeira5); Oi Telecom (com

\footnotetext{
${ }^{4}$ Disponível em http://www.dnrc.gov.br/Legislacao/normativa/in81.htm. Acesso em 01/12/2013.

${ }^{5 “} \mathrm{O}$ numero de acionistas, em dezembrode 2012, somou 5.549, com aproximadamente $85 \%$ do capital da Companhia detido por estrangeiros". Disponível em: http://portal.lojasrenner.com.br/renner/ri/index.htm. Acesso em 01/12/2013. Conjuntura Global, Curitiba, Vol.2, n.4, out./dez., 2013, p. 214-221.
} 
25,6\% da participação sob controle da Portugal Telecom6); PUC-RS;

e Aliança Francesa.

- Instituições Estrangeiras: Banco Santander (Santander, Espanha);InstitutFrançais ${ }^{7} \quad$ (Paris, França); SAP AG (Systeme, Anwendungenund Produkte in der Datenverarbeitung em Walldorf, Alemanha);Timac Agro Brasil (Grupo Roullier em SaintMalo, França); a IBM (International Business Machinea emNova York, Estados Unidos); e a Évora Holding Company (antiga Petropar, Paraguai).

As instituições e empresas estrangeiras têm, em sua maioria, suas sedes administrativas na União Europeia, seguida por uma nos Estados Unidos e outra no Paraguai. Essas empresas, sediadas na França, Alemanha e Espanha atuaram diretamente na execução da Bienal. Por atingirem grande índice de ativos e funcionários, suas participaçõesimpactam nas dinâmicas locais através de seus investimentos estrangeiros - tanto por repasse de capital privado ao público, em impostos e empregos, por exemplo, como por repasse direto através de seus investimentos e financiamentos de eventos como o analisado.

O Banco Santander consta como sexto maior banco segundo classificação feita em 2013 pelo Banco Central do Brasile, tendo R\$ 475.021.713,00 de ativo total. Apesar de possuir uma sede administrativa no Estado de São Paulo, sua sede internacional e originária ainda encontra-se na Espanha. A SAP AG (Sistemas, Aplicativos e Produtos para Processamento de Dados) é uma empresa de gestão tecnológica e de dados que possui sua sede na Alemanha e a Timac Agro Brasil é uma empresa de produtos voltados

\footnotetext{
${ }^{6}$ Disponível em: http://www.telecom.pt/InternetResource/PTSite/PT/Canais/Investidores/Grupo/estrategia/intl/intl.ht

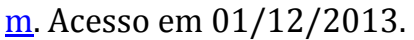

7 “L'Institutfrançais est l'opérateur de l'actionculturelleextérieure de la France. Il a étécréé par laloidu 27 juillet 2010 relative à l'actionextérieure de l'État et par sondécret d'applicationdu 30 décembre 2010". Disponível em: http://www.institutfrancais.com/fr/faites-notre-connaissance.Acesso em 01/12/2013.

8 Disponível em: http://www4.bcb.gov.br/fis/T0P50/port/Top50P.asp. Acesso em 01/12/2013.

Conjuntura Global, Curitiba, Vol.2, n.4, out./dez., 2013, p. 214-221.
} 
à produção agrícola pertencente ao grupo francês Roullier. Essas três empresas, por mais submetidas à legislação e produção brasileiras, possuem um mínimo de controle de investimentos e lucros em suas sedes europeias, mantendo a ideia de capital estrangeiro.

\section{Ação empresarial na Bienal do Mercosul}

Dada realidade jurídica brasileira, instituições privadas, de acordo com políticas fiscais, podem direcionar parte de seu capital às ações sociais. A partir de 2004, com a Lei PPP (Lei Federal no 11.079 de 30 de dezembro de 2004 referente à Parceria PúblicoPrivada), a cooperação entre o capital público e o privado também torna possível a resolução comum de desafios, como construção de infraestrutura e outras obras que antes limitavam-se à iniciativa pública. Com esse cenário, a participação de empresas multinacionais e transnacionais nas dinâmicas sociais regionais no Brasil amplia-se para além das obrigações fiscais.

Logo, quais seriam os interesses dessas empresas em participarem da IX Bienal do MERCOSUL? Como dito anteriormente, além das diretrizes fiscais, o evento torna-se: divulgador das marcas; e contribuinte na construção de uma identidade social positiva, ou seja, de agentes engajados ao desenvolvimento social local através do apoio à cultura. Essa participação empresarial nas dinâmicas sociais também passam, em um segundo momento, a contribuir junto ao processo de integração regional do MERCOSUL, dentro da perspectiva de novos atores. Para tanto, expõe-se nesse boletim participações e interesses junto ao evento, bem como a relevância dentro do processo de integração regional que esses novos atores podem adquirir.

Diversas pesquisas já mostraram que processos de integração regional são favoráveis ao desenvolvimento empresarial e ampliação de seus campos de atuação. Estudos, ainda nos anos 1990 (LEAL; SILVA, 1998), mostram que o MERCOSUL, por exemplo, favoreceu a integração dos mercados argentino e brasileiro. A participação de empresas europeias junto ao processo de integração regional, tendo em vista facilidades comerciais não é novidade. 0 interesse empresarial nesse processo de integração de Conjuntura Global, Curitiba, Vol.2, n.4, out./dez., 2013, p. 214-221. 
mercados não seria apenas observado apenas em políticas comerciais, mas também em sua atuação junto às comunidades e seus ritos. A Bienal do MERCOSUL, como uma produção da sociedade civil organizada, também instrumentalizaria esses interesses.

No caso do Banco Santander (espanhol), da SAP AG (alemã) e do Grupo Roullier (francês), pode-se dizer que essas empresas aportaram no Brasil após os vários processos de expansão no próprio continente europeu, encontrando aqui um cenário de desenvolvimento inicial do MERCOSUL, tendo que, inicialmente, fortalecer suas marcas junto às comunidades regionais. A inserção comercial de produtos e serviços necessita de visibilidade e, eventos como a Bienal do MERCOSUL, pode gerar uma visibilidade muito maior do que a ação local, mas a própria propaganda favorável ao processo de integração de mercados. Ao financiarem sua execução, ligam suas marcas de produtos e serviços à ideia de MERCOSUL e, consequentemente, à ideia de integração regional. Esse envolvimento, como já levantado anteriormente, pode ser explicado pelos interesses de ampliar suas atuações a um mercado maior.

Diversos eventos e projetos sociais já receberam apoio do capital privado dessas empresas e, no caso da Bienal, pode-se defender que esses interesses empresariais, por uma maior visibilidade e inserção no mercado dos Estados membros do MERCOSUL, contribuiriam na justificativa da participação das mesmas em um evento cultural. $\begin{array}{lllll}\text { Segundo a } & \text { Fundação Bienal do MERCOSUL }\end{array}$ (http://9bienalmercosul.art.br/pt/sobre/parceiros/) torna-se pública a descrição das especificidades de apoio por cada empresa exposta: o Banco Santander patrocinou a exposição Portais, Previsões e Arquipélagos, bem como foi um dos principais apoiadores institucionais do evento; a SAP AG tornou-se apoiadora do Programa Invenções Caseiras; e a Timac Agro foi denominado "incentivador diamante" junto ao Projeto Pedagógico do evento.

A exposição coletiva Portais, Previsões e Arquipélagos reuniu diversas obras e abordou "a arte como portais para outros mundos - imaginações, explorações e manifestações do que está abaixo e acima do plano social". Aproximadamente 60 artistas nacionais e internacionais participaram do evento, bem como o público em geral, colocando a Bienal do MERCOSUL em uma visibilidade a nível regional muito Conjuntura Global, Curitiba, Vol.2, n.4, out./dez., 2013, p. 214-221. 
importante. Muitos artistas e público visitante moram ou nasceram nos países do MERCOSUL, contribuindo estrategicamente com o fortalecimento da marca Santander na região como instituição parceira da cultura local. Todavia, a cultura europeia, trazida por seus artistas também responde quase a metade das obras presentes. A participação, não apenas do capital, mas do discurso cultural europeu também esteve presente, possibilitando outros questionamentos neocoloniais que fogem do proposto. 0 Banco Santander, portanto, possuiu visibilidade durante toda execução dessa que foi a principal exposição coletiva da Bienal.

Já as empresas SAP AG e Timac Agro buscaram contribuir na formação técnica e pedagógica dos espectadores e das comunidades locais às quais recebiam serviços de ensino junto ao evento. A SAP AG atuou como incentivadora de invenções caseiras, interessada em descobrir novos talentos na região, bem como ligar sua marca ao empreendedorismo tecnológico que faz parte de sua natureza empresarial. Já a Timac Agro, ao envolver-se com o Projeto Pedagógico, a empresaafirmou sua marca através de redes de formação, que durou do mês de maio até novembro de 2013, para "educadores, mediadores e público interessado" 9 , bem como exposta em "encontros, workshops, convocatórias, residências e conferências"10. De modo geral, ambas expusera suas marcas, produtos e serviços de forma direta à sociedade local e regional, valorizando tanto suas marcas como agentes sociais, bem como atingindo um público amplo e internacional.

\section{Considerações Finais}

A ação internacional de empresas requer reconhecimento de suas marcas de forma positiva pelo público. Ao financiar e apoiar a realização da IX Bienal do MERCOSUL, instituições como o Banco Santander, SAP AG e Timac Agro, de origens europeias, conseguem não apenas fortalecer suas identidades de forma positiva com a comunidade - respaldada no sucesso do evento - como também alcançam um público muito maior que o local ou o nacional brasileiro.

\footnotetext{
${ }^{9}$ Disponível em: http://9bienalmercosul.art.br/pt/redes-de-formacao/. Acesso em 01/12/2013. ${ }^{10}$ Disponível em: http://9bienalmercosul.art.br/pt/redes-de-formacao/. Acesso em 01/12/2013. Conjuntura Global, Curitiba, Vol.2, n.4, out./dez., 2013, p. 214-221.
} 
O vínculo de suas marcas com um evento que leva em seu nome a palavra MERCOSUL também fortalece a ideia de apoio ao processo de integração regional ao nível cultural, ainda que dos governos nacionais a Bienal receba apenas apoio do Brasil. A IX Bienal do MERCOSUL torna-se um bom exemplo de ação entre diversos atores: Estado, governos subnacionais, empresas, sociedade civil e organizações nãogovernamentais, como a própria Fundação Bienal do MERCOSUL (uma ONG). As dinâmicas e processos comerciais internacionais fortalecem seu caráter transnacional dentro dos grandes blocos de integração regional, como o MERCOSUL, visto em diversas outras pesquisas sobre integração de mercado.

Fortalecer suas marcas na regiãotorna-se uma ação mais complexa do que apenas a propaganda tradicional em veículos de comunicação em massa. As empresas analisadas mostram-se preocupadas em fortalecer uma identidade positiva e, de forma suave, demonstrar seus interesses nos processos que cabem à esfera política integração regional - tomando para si iniciativas locais ao nível econômico-cultural. A IX Bienal do MERCOSUL, portanto, torna-se um instrumento para que essas empresas ganhem maior inserção no mercado local, nacional e regional do MERCOSUL.

\section{Referências Bibliográficas}

9a Bienal do MERCOSUL. Disponível em: http://9bienalmercosul.art.br/. Acesso em 01/12/2013.

Fundação Bienal do Mercosul. Disponível em:http://www.fundacaobienal.art.br/. Acesso em 01/12/2013.

LEAL, Ricardo Pereira Câmara; SILVA, Giovani Pereira. O MERCOSUL e a integração regional dos mercados acionários argentino e brasileiro. Disponível em: http://www.scielo.br/scielo.php?pid=S0034-

$\underline{75901998000400005 \& s c r i p t=s c i ~ a r t t e x t}$. Acesso em 01/12/2013.

Conjuntura Global, Curitiba, Vol.2, n.4, out./dez., 2013, p. 214-221. 